\title{
Lipid profile, Beta-lipoprotein shift ratio and serum glucose in metabolic syndrome patients
}

\author{
Mohammad A. AL-Kataan \\ Department of Clinical pharmacy, College of pharmacy \\ University of Mosul
}

Received: Accepted

\begin{abstract}
\end{abstract}
Objectives: (a) To determine the change in the lipid profile, $\beta$-lipoprotein shift ratio (B-LSR) and serum fasting glucose (SG) in metabolic syndrome( MS) and control.(b) To determine the effects of age and body mass index (BMI) on the measured parameters.

Methods: This study was conducted in AL-Darkeslea area in Mosul province. during the period from January to April r...v. Fasting blood samples were collected from '.. patients, 7 . patients with metabolic syndrome MS according to WHO criteria and $\varepsilon$ - apparently healthy subjects. The collected data were analysed by $r$ - sample t-test and the effects of the age and BMI on the measured parameters were determined by correlation coefficient.

Results: B-LSR was higher in MS patients than in the control group $(\mathrm{P}<\cdot \ldots 1)$, Total serum cholesterol (TC), triglycerides (TG), Low density lipoprotein-cholesterol (LDL-C), Very low density lipoprotein-cholesterol (VLDL-C) and atherogenic index (AI)showed significant increases in MS patients when compared to the controls $(\mathrm{P}<\because .0)$, while serum high density lipoprotein-cholesterol (HDL-C) showed significant reduction in MS than controls $(P<\cdot .+1)$, also SG showed same increase $(P<\cdot, \cdot 1) . T C$ and LDL-C were significantly correlated with the age in controls while no significant correlation were seen in the MS patients. No significant correlation was noticed between BMI and the measured parameters, in both MS patients and control group.

Conclusion: MS is associated with significant changes in B-LSR, lipid profile and SG. Age and BMI showed no significant correlation with theses parameters in the MS patients.

الخداف الخة

أهداف الدراسة : بيان التغير الحاصل في واجهة شحوم الدم ، ونسبة تحول البروتين ألثحمي-بيتاو مستوى السكر في بـاي

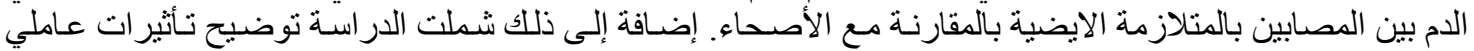

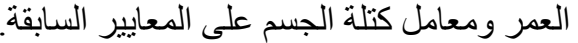

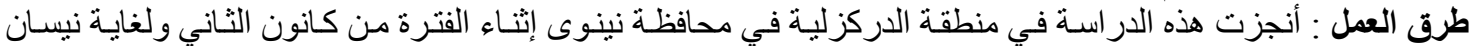

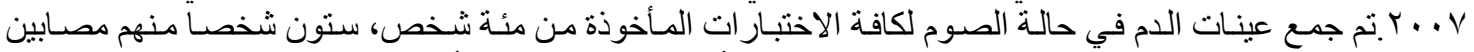

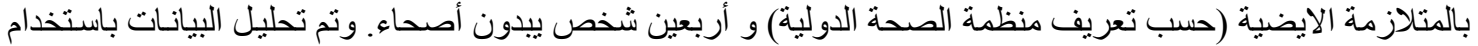

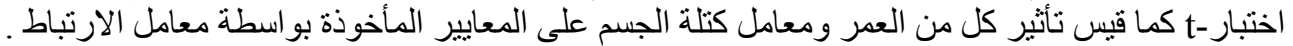

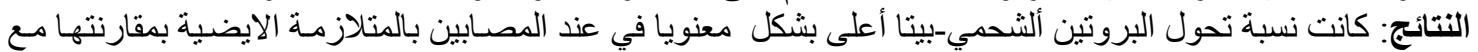
الأصحاء عند (ب > ا . . . •). كما لوحظ ارتفاع في كل من مستوى الكوليستيرول الكلي، الثـحوم الثلاثيـة، كوليستيرول

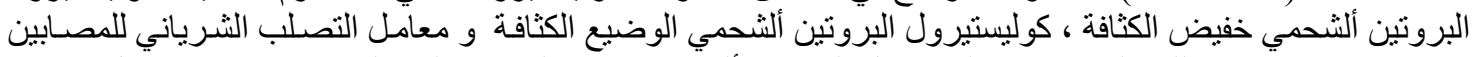

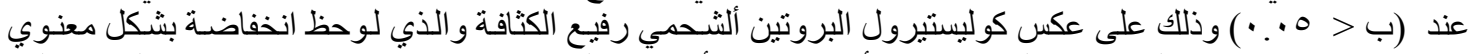

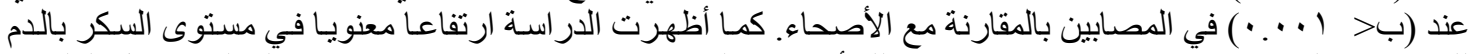

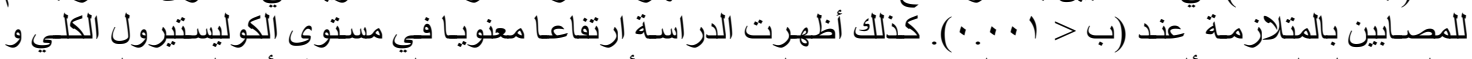

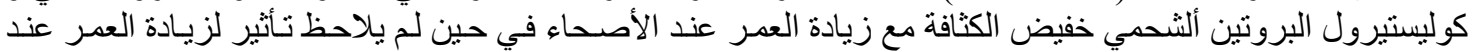

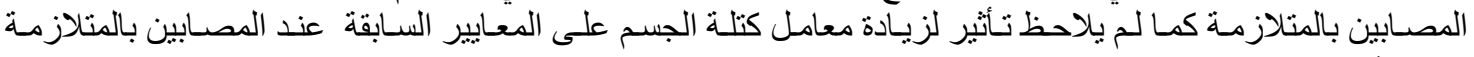

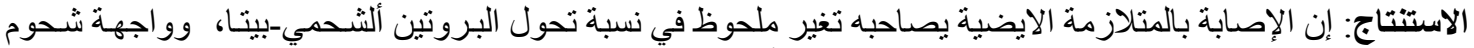

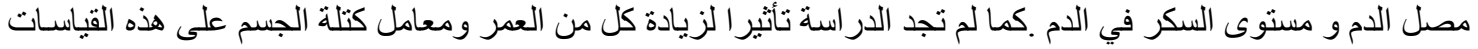
عند المصابين بالمتلازمة مة الايضية. 
$\mathrm{M}$ etabolic syndrome (MS), is insulin resistance syndrome or syndrome $X$, it also includes abdominal obesity, elevated blood pressure, and lipid abnormalities and microalbuminuria., $, r, r$ World health organization (WHO) defined metabolic syndrome as: the co-occurrence of any three of the abnormalities: central obesity with body mass index $(\mathrm{BMI})>\mathrm{r}_{0}$ $\mathrm{Kg} / \mathrm{m}^{r}$, high blood pressure $>1 \varepsilon \cdot / 1 \cdot \mathrm{mm}$ $\mathrm{Hg}$, serum fasting glucose $>\mathrm{V} \mathrm{mmol} / \mathrm{L}$, total serum cholesterol>0. $1 \wedge \mathrm{mmol} / \mathrm{L}$.,

Epidemiology and prevalence of metabolic syndrome varies by definition used and population studied.' Based on data from the Third National Health and Nutrition Examination Survey (1911 to 199\&), the prevalence of metabolic syndrome varies from 17 - TV percent ${ }^{\vee}$. The prevalence of metabolic syndrome increases with aging and body weight:. ${ }^{\wedge}$ "The etiology of the metabolic syndrome has not been established definitely. One hypothesis presumed that the primary cause is insulin resistance. Insulin resistance correlates with visceral fat measured by waist circumference, waist to hip ratio or BMI. The link between insulin resistance and cardiovascular disease probably is mediated by oxidative stress, which produces endothelial cell dysfunction, promoting vascular damage and atheroma formation.' The second hypothesis blamed hormonal changes for the development of abdominal obesity.,,9 Patient with elevated levels of serum cortisol (caused by chronic stress) developed abdominal obesity, insulin resistance and lipid abnormalities." This study was conducted to evaluate the changes that occur in MS patients in $\beta$ lipoprotein shift ratio (B-LSR), lipid profile and serum fasting glucose (SG). Also the study included the correlation between of age or BMI and the measured parameters.

\section{Subjects and methods}

This study was conducted in period from
January through April $r \ldots v$ in Private clinics in Al- Drkeslea area in Mosul. One hundred subjects were divided into two groups: The first group included \&. apparently healthy individuals as controls and 7 . individuals with MS according to the WHO criteria. ${ }^{\xi}, 0$ Serum fasting glucose was assayed by glucose oxidase /peroxidase colorimetric method " ${ }^{r}$, TC by Richmond-enzymatic method'", high density lipoprotein- cholesterol(HDL-C) measured by Lopez-Virella method'sand triglycerides (TG) were measured by Fossati-enzymatic method ${ }^{\prime}$. While Low density lipoprotein-cholesterol (LDL-C), Very low density lipoprotein-cholesterol (VLDL-C), atherogenic index (AI), $\beta$-LSR were calculated using equations. ${ }^{17,1 /}$ Data were presented as mean $\pm S D$, r-sample ttest and the effects of increase age, BMI on measured parameters were determined by correlation.

\section{Results}

Table 1 shows that, B-LSR in MS patients was higher than controls $(P<\cdot . . \cdot 1)$, furthermore, lipid profile parameters showed significant increase in MS patient $(P<\cdot . \cdot 0)$ while HDL-C showed significant decrease in MS when compared to the controls $(P<\cdot . .1)$.Serum glucose level demonstrated significant increase in MS patients $(\mathrm{P}<\cdot . .1)$ when compared to the controls.

This study included evaluation the effects of aging on measured parameters and compared these value to the control value. The results revealed that with increasing the age, TC and LDL-C showed significant increase in control group, while no significant changes occur in the measured parameters with aging in MS patients.

The study also used BMI as indicator for increase in the body weight to show its effect on the on measured parameters. The results showed that there were no significant changes with increase BMI in MS patients. 
Table '. Lipid profile, beta-lipoprotein shift ratio and serum glucose in metabolic syndrome patients and controls.

\begin{tabular}{|c|c|c|}
\hline Parameter & $\begin{array}{c}\text { Controls } \\
\mathrm{N}=\varepsilon\end{array}$ & $\begin{array}{l}\text { Metabolic syndrome patients } \\
\qquad \mathrm{N}=\uparrow .\end{array}$ \\
\hline Total serum cholesterol $\mathrm{mmol} / \mathrm{L}$ & $0 . r \leqslant \pm \cdot . \varepsilon 7$ & $7 . \leqslant \wedge \pm \cdot .79 * * *$ \\
\hline Triglycerides $\mathrm{mmol} / \mathrm{L}$ & $1.70 \pm \cdot .10$ & $1 . \wedge 1 \pm \cdot . \varepsilon 0^{* *}$ \\
\hline High density lipoprotein $\mathrm{mmol} / \mathrm{L}$ & $1 . \cdot \leq \pm \cdot .17$ & $\cdot . \wedge \wedge_{ \pm} \cdot 1^{1 / * *}$ \\
\hline Low density lipoprotein $\mathrm{mmol} / \mathrm{L}$ & $r .07 \pm \cdot . r q$ & $\varepsilon . \wedge \pm \cdot .00 * * *$ \\
\hline Very low density lipoprotein $\mathrm{mmol} / \mathrm{L}$ & $\cdot V \leq \pm \cdot .1 r$ & $\cdot \wedge \perp \pm \cdot \cdot r^{*}$ \\
\hline Atherogenic index & $0 . Y \leq \pm \cdot . M \Lambda$ & $V .0 \pm 1 . r V^{* * *}$ \\
\hline Beta-lipoprotein Shift ratio & $r .1 \wedge \pm \cdot . r 4$ & $\curlyvee . \wedge \pm \pm \cdot .77^{* * *}$ \\
\hline Serum glucose $\mathrm{mmol} / \mathrm{L}$ & $0.1 \leq \pm . . r 4$ & $r . Q_{ \pm \pm} \cdot r_{0 * * *}$ \\
\hline
\end{tabular}

${ }^{*}<\cdot . .0,{ }^{* *} \mathrm{P}<\cdot . \cdot 1,{ }^{* * *} \mathrm{P}<\cdot, . \cdot 1$

\section{Discussion}

In the present study the increase in the B-LSR in the MS patients may be due to the increase in the serum TG. The increase in the flux of free fatty acids (FFA)from the periphery to the liver causes stimulation of hepatic TG synthesis. '^ Insulin resistance and hyperglycemia increase intracellular Malonyl Co-A concentration which intern inhibit Carnitine Palmitoyl Transferase (CPTI) that responsible for entrance of FFA to mitochondria leading to more VLDL formation. ${ }^{19}$ B-LSR reflect the hepatic lipase $(\mathrm{HL})$ activity the compensatory mechanism to decrease dyslipidemic effect of the disease, so the continuous increase in the serum VLDL formation will lead to continuous stimulation HL-activity. ${ }^{\text {." }}$

The high TC in the present MS patients are consistent with Mazzone and Sandhfer" could be explained by increase in Apo-B lipoprotein assembly, that produce by conversion of VLDL to IDL and LDL by the action of $\mathrm{HL}^{r \cdot}$ Also the down regulation of Apo-B receptor that lead to significant decrease in the LDL clearance ${ }^{r r}$, moreover increase in cholesteryl ester transferring protein (CETP). ${ }^{r r}$

The present study showed significant reduction in the HDL-C level in the MS patients and this probably are due to either decrease number of $\mathrm{HDL}$ particle or the carrying capacity. Reilly and Rader ${ }^{r \xi}$ described similar reduction, this reduction occurs secondarily to increase in the TG that occur with increase in the CETP to form TG-rich HDL particle that prone to catabolism more than binding. Another possible mechanism described also by Reilly and Rader ${ }^{r \xi}$ which relate the decrease in the HDL to the reduction in hepatic Apo-A formation. Brewer et al $^{\text {ro }}$ described a third possible mechanism, the significant reduction in the HDL occur as a result of defect in the ATP-dependent binding cascade $A_{1}$ transporting system $\left(A B C A_{1}\right)$ leading to destabilization of HDL-particle.

Hyperglycemia in the present MS-patients can be explained by increase in the insulin resistance that in turn cause intracellular deprivation of glucose as described by Ruderman $^{r}$. The increase in both serum glucose and fructose provided substrate for more FA and glycerol synthesis leading to increase in serum TG. ${ }^{r Y, Y \wedge}$ The change in the intracellular cytoplasmic $\mathrm{Mg}^{++} / \mathrm{Ca}^{++}$ratio can also interfere with normal insulin secretion and its normal activity. ${ }^{r q, r}$. The abnormal high adrenergic activity is due to low intracellularcytoplasmic $\mathrm{Mg}^{++}$which lead to increase serum glucose and increase gluconeogenesis, glycogenolysis and lipolysis."

This study shows no significant correlation on the measured parameters with age and $\mathrm{BMI}$ in MS patients and this result controverts the result obtained by Scott. "In conclusion MS patients have significant changes in BLSR, lipid profile and SG that lead to increase in the morbidity and mortality. Age show no 
significant correlation to MS in this group of patients.

\section{References}

1. Vega G L. Obesity, the metabolic syndrome, and cardiovascular disease. Am

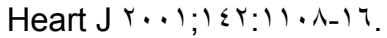

$r$. Reaven G M. Role of insulin resistance in human disease. Diabetes 1911;rV:1090_ $17 . \mathrm{V}$.

r. Lamarche B, Tchernof A, Mauriege $P$, Cantin B, Dagenais GR, Lupien PJ. Fasting insulin and apolipoprotein $B$ levels and lowdensity lipoprotein particle size as risk factors for ischemic heart disease. JAMA 1994; rV9:1900-71.

£. National Institutes of Health: Third Report of the National Cholesterol Education Program Expert Panel on Detection, Evaluation, and Treatment of High Blood Cholesterol in Adults (Adult Treatment Panel III). JAMA $r$. I ; r $r 0 ;$ TA-90

-. Alberti KG, Zimmet PZ. Definition, diagnosis and classification of diabetes mellitus and its complications. Part 1: diagnosis and classification of diabetes mellitus, provisional report of a $\mathrm{WHO}$ consultation. Diabet Med 1991; 10:0r9_or.

7. Ford ES, Giles WH. A comparison of the prevalence of the metabolic syndrome using two proposed definitions. Diabetes

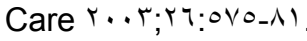

v. Ford ES, Giles WH, Dietz WH. Prevalence of the metabolic syndrome among U.S. adults: findings from the Third National Health and Nutrition Examination Survey. JAMA r..r; rAV:ror-q.

^. Eckel RH, Krauss RM. American Heart Association call to action: Obesity as a major risk factor for coronary heart disease. AHA Nutrition Committee. Circulation 199८; १४:r. १9-1...

9. Grundy SM, Brewer HB Jr, Cleeman JI, Smith SC Jr, Lenfant C. Definition of metabolic syndrome: Report of the National Heart, Lung, and Blood Institute/American Heart Association conference on scientific issues related to definition. Circulation r.. $\varepsilon ; 1 \cdot 9: \varepsilon r r-\wedge$.
1..Lopez-Candales A. Metabolic syndrome X: a comprehensive review of the pathophysiology and recommended

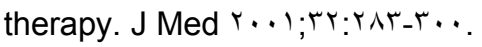

11. Bjorntorp P. Heart and soul: stress and the metabolic syndrome. Scand Cardiovasc $\mathrm{J}$ r...; ro: YVr-Y.

Ir.Lotta JA, Turner K . Evaluation of trinder's glucose oxidase method for measuring glucose in serum and urine. Clin Chem 19V0; r I: V VO $-1 Y T$.

1T. Richmond W. Preparation and properties of a cholesterol oxidase from nocardia $\mathrm{Sp}$. and its application to the enzymatic assay of Total serum cholesterol in serum. Clin Chem 19Vr;19:1 ro.-1ror.

I s.Lopez - Virella MF, Stone P, Colwell JA . Cholesterol determination in high density lipoproteins separated by three different methods. Clin Chem 1 $9 \vee v ; r r: \wedge \wedge r-\wedge \wedge \varepsilon$.

10. Fossti $P$, Prencipe $L$. Serum triglycerides determination colorimtrically with an enzyme that produces hydrogen peroxides. Clin Chem 19Ar;rA:r.VV-r.10.

17. Bishop M., Fody E., Schoeff L. Clinical Chemistry : Procedures, Principles and Correlation. Lippincott Williams New York,USA. Y . . O: r. Y-r.r.

iv. Katzung B. Basic and Clinical Pharmacology. Mc Grow Hill, Boston, USA.Y... : OTY_oTY.

1^.Jheem D ,Susan L, Glenna L,John H. Hepatic triglycerides lipase promote LDLreceptor-mediated catabolism of VLDL in Vitro. Journal of Lipid Research 1999; irtr-IrVo.

19. Neil RB, Saha KA. Metabolic syndrome: Adenosine mono-phosphate activated protein kinase and Malonyl Co-A . Obesity r... r; $) \leqslant: r 0-r r$.

$r \cdot$ Bagby S. Obesity-initiated metabolic syndrome and the kidney: Arecipe for chronic kidney disease. J Am Nephrol r...; ; $0:$ TVVO-rVq1.

r. Mazzone T, Foster D, Chait A. In vivo stimulation of low-density lipoprotein degradation by insulin. Diabetes

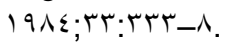

rr.Sandhofer A, Kaser S, Ritsch A. Cholesteryl-ester transfer protein in 
$r^{r}$. metabolic syndrome. Obesity $r_{\cdots}, \tau ; 1 \leqslant: \wedge \mid r_{-}$ ᄉ).

$r \varepsilon$.Ginsberg HN, Huang LS. The insulin resistance syndrome: impact on lipoprotein metabolism and atherothrombosis. J Cardiovasc Risk r...; ; rro_rl.

ro. Reilly MP, Rader DJ. The metabolic syndrome: more than the sum of its parts? Circulation r...r;1. 1 : 10 $0 \leq 7+01$.

r.. Brewer HB, Renaly AT, Basso F.Regulation of plasma HDL lipoprotein level by the $A B C A$ l transporter and emerging role of HDL Lipoprotein in the treatment of cardiovascular disease. Ateriosclor Thromb Vasc Biol r...; rs:1v00_lvr.

$r \vee$.Ruderman N B, De Groot, Jameson L J. The metabolic syndrome Endocrinology, $0^{\text {th }}$ edition Elsevier Philadelphia, U.S.A.Y.. $11 \leq 9-1177$.
r^.Resnick L. Cellular Ca and Mg metabolism in the pathophysology and treatment of hypertension and related metabolic disorders. Am J Med 199r;9r: 110-r.0.

rq.Boden, G, Jadali, F, White, J. Effects of fat on insulin-stimulated carbohydrate metabolism in normal men. J Clin Inves 1991; $14: 97 .-977$.

$r \cdot$ Boullin DJ.The action of extra-cellular Cations on the release of sympathetic transmitter from peripheral nerve. J Physol 197v;1 19:10-99.

r. Seelng MS. Consequences of $\mathrm{Mg}$ deficiency, enhancement of stress action , preventive and therapeutic implication. J

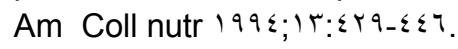

rr.Scott M, Brewer H, Cleeman I,Smith C.Definition of metabolic syndrome: Report of national heart ,lung and blood institute/American heart association conference. Circulation r.. $\leqslant ; \varepsilon r r-\varepsilon r \wedge$. 